\title{
Treated hydrocephalus in individuals with myelomeningocele in the National Spina Bifida Patient Registry
}

\author{
Irene Kim, MD, ${ }^{1}$ Betsy Hopson, MHSA, ${ }^{2}$ Inmaculada Aban, PhD, ${ }^{3}$ Elias B. Rizk, MD, ${ }^{4}$ \\ Mark S. Dias, MD, ${ }^{4}$ Robin Bowman, MD, ${ }^{5}$ Laurie L. Ackerman, MD, ${ }^{6}$ \\ Michael D. Partington, MD, MS, ${ }^{7}$ Heidi Castillo, MD, ${ }^{8}$ Jonathan Castillo, MD, MPH, ${ }^{8}$ \\ Paula R. Peterson, MS, ${ }^{9}$ Jeffrey P. Blount, MD, ${ }^{2}$ and Brandon G. Rocque, MD, MS ${ }^{2}$
}

\begin{abstract}
${ }^{1}$ Department of Neurosurgery, Medical College of Wisconsin, Milwaukee, Wisconsin; ${ }^{2}$ Department of Neurosurgery, University of Alabama at Birmingham, Children's of Alabama, Birmingham; ' 3 Department of Biostatistics, University of Alabama at Birmingham, Birmingham, Alabama; ‘Department of Neurological Surgery, Penn State College of Medicine, Hershey, Pennsylvania; ${ }^{5}$ Pediatric Neurosurgery, Lurie Children's Hospital of Chicago, Illinois; ${ }^{6}$ Goodman Campbell Brain and Spine Division of Pediatric Neurosurgery, Department of Neurological Surgery, Indiana University School of Medicine, Indianapolis, Indiana; 'Department of Neurosurgery, University of Kansas, Kansas City, Kansas; ${ }^{8}$ Department of Pediatrics, Baylor College of Medicine, Houston, Texas; and ${ }^{~}$ Department of Neurology, University of Utah, Salt Lake City, Utah
\end{abstract}

OBJECTIVE Although the majority of patients with myelomeningocele have hydrocephalus, reported rates of hydrocephalus treatment vary widely. The purpose of this study was to determine the rate of surgical treatment for hydrocephalus in patients with myelomeningocele in the National Spina Bifida Patient Registry (NSBPR). In addition, the authors explored the variation in shunting rates across NSBPR institutions, examined the relationship between hydrocephalus, and the functional lesion level of the myelomeningocele, and evaluated for temporal trends in rates of treated hydrocephalus.

METHODS The authors queried the NSBPR to identify all patients with myelomeningoceles. Individuals were identified as having been treated for hydrocephalus if they had undergone at least 1 hydrocephalus-related operation. For each participating NSBPR institution, the authors calculated the proportion of patients with treated hydrocephalus who were enrolled at that site. Logistic regression was performed to analyze the relationship between hydrocephalus and the functional lesion level of the myelomeningocele and to compare the rate of treated hydrocephalus in children born before 2005 with those born in 2005 or later.

RESULTS A total of 4448 patients with myelomeningocele were identified from 26 institutions, of whom 3558 patients $(79.99 \%)$ had undergone at least 1 hydrocephalus-related operation. The rate of treated hydrocephalus ranged from $72 \%$ to $96 \%$ among institutions enrolling more than 10 patients. This difference in treatment rates between centers was statistically significant $(p<0.001)$. Insufficient data were available in the NSBPR to analyze reasons for the different rates of hydrocephalus treatment between sites. Multivariate logistic regression demonstrated that more rostral functional lesion levels were associated with higher rates of treated hydrocephalus $(p<0.001)$ but demonstrated no significant difference in hydrocephalus treatment rates between children born before versus after 2005.

CONCLUSIONS The rate of hydrocephalus treatment in patients with myelomeningocele in the NSBPR is $79.99 \%$, which is consistent with the rates in previously published literature. The authors' data demonstrate a clear association between functional lesion level of the myelomeningocele and the need for hydrocephalus treatment.

https://thejns.org/doi/abs/10.3171/2018.5.PEDS18161

KEYWORDS myelomeningocele; spina bifida; hydrocephalus; VP shunt; congenital

ABBREVIATIONS CDC = Centers for Disease Control and Prevention; MOMS = Management of Myelomeningocele Study; NSBPR = National Spina Bifida Patient Registry . SUBMITTED March 21, 2018. ACCEPTED May 25, 2018.

INCLUDE WHEN CITING Published online August 24, 2018; DOI: 10.3171/2018.5.PEDS18161. 
$\mathrm{T}$ HE majority of patients with a diagnosis of myelomeningocele have concomitant hydrocephalus. Rates of CSF diversion for treatment of hydrocephalus vary widely, ranging from $40 \%$ to $91 \%$ in the published literature (52\% to $91 \%$ for postnatal myelomeningocele closures). ${ }^{1-4,7,10,13}$ In the randomized trial Management of Myelomeningocele Study (MOMS), rates of shunting were $40 \%$ in the prenatal-surgery group and $82 \%$ in the postnatal-surgery group at 12 months of age, but this trial included only mothers who met stringent selection criteria, and less than $20 \%$ of screened mothers were enrolled. ${ }^{1}$

Although the association between myelomeningoceles and hydrocephalus is well established, there are far fewer data on the relationship between the functional lesion level of the myelomeningocele and the need for hydrocephalus treatment. One large retrospective review of 297 individuals found that rates of shunt placement varied with both the functional and anatomical levels of the myelomeningocele, with higher rates of shunting required in patients with more rostral lesion levels. ${ }^{10}$ However, another retrospective analysis of 72 patients found no difference in shunting rates by anatomical level. ${ }^{8}$

In 2008, the Centers for Disease Control and Prevention (CDC) established the National Spina Bifida Patient Registry (NSBPR) to facilitate research and improve clinical care for children and adults with spina bifida. ${ }^{12,14}$ The NSBPR collects data longitudinally, using both family/patient reports and medical record review at the time of routine clinic visits. It includes multiple checks on data integrity and quality (see Appendix for details of the NSBPR and data collection techniques). The majority of participants in the NSBPR have myelomeningocele, with other forms of spinal dysraphism in $<20 \%$ of all participants. ${ }^{12}$

The goal of this study was to use data collected in the NSBPR to better understand the treatment of hydrocephalus among individuals with myelomeningocele. In addition, we sought to examine the variation of rates of treated hydrocephalus between centers participating in the NSBPR. We also explored the relationship between rates of CSF shunting and the functional lesion level of the myelomeningocele. Lastly, we sought out any temporal trends in the rates of hydrocephalus treatment for patients with myelomeningocele.

\section{Methods}

Much of the methods in this study has been reported in another paper by our group. ${ }^{5}$ Data collection for the NSBPR is performed at each site by a designated coordinator. Variables to be collected are noted at the time of the clinic visit on standardized case report forms (either an Initial Encounter Form or an Annual Collection Form) following the NSBPR Manual of Procedures. Data are obtained from query of the patient/family, review of the medical record, or both. Data are then uploaded to an NSBPR electronic record. Here, they are automatically subjected to data quality checks. Additional checks are performed by NSBPR administrators and requests for clarification sent to each site. Full details of the NSBPR data collection procedure can be found in the Appendix.

Per the established protocol for studying the aggregate data collected in the NSBPR, the data analysis proposal for this study was reviewed by the CDC Committee for Science and Publication. We then queried the NSBPR to identify all patients with myelomeningocele enrolled in the registry between March 2009 and October 2015. We collected demographic and clinical variables and records of all included operative procedures. Operative procedures may have been performed outside of the 2009-2015 time range, since those performed prior to NSBPR enrollment would be recorded at the time of enrollment. The functional lesion level was determined by direct bilateral lower-extremity neurological examination. If the lesion differed by side, the more rostral level was used to represent the functional lesion level. We defined individuals as having treated hydrocephalus if they had a history of one or more qualifying hydrocephalus-related operations (Table 1).

We calculated the rate of treated hydrocephalus among all patients with myelomeningocele. We assumed that hydrocephalus is treated within the first few months of age, and therefore, that including all patients in the analysis is valid. However, to control for the possibility that very young children may not yet have received treatment, we also determined the rate of hydrocephalus treatment excluding all children younger than 12 months.

Univariate logistic regression was used to examine the relationship between the treatment of hydrocephalus and the functional lesion level of the myelomeningocele. For each participating institution in the NSBPR, we calculated the proportion of patients enrolled at that site with treated hydrocephalus. Chi-square analysis was performed to determine if the difference in the hydrocephalus treatment rate between institutions was statistically significant.

It is our perception that, in recent years, there has been a trend toward a higher threshold for treatment of hydrocephalus in patients with myelomeningocele. To explore this, univariate logistic regression was used to compare the rates of treated hydrocephalus between patients born before 2005 and those born in 2005 or later. The year 2005 was selected by consensus opinion of the authors. Because 2005 was chosen by consensus and without empirical support, sensitivity analysis was performed by repeating analysis using 2002 and 2008 as the cutoff years. Additional sensitivity analysis was performed comparing rates of hydrocephalus treatment for children born in 2003

TABLE 1. List of hydrocephalus-related procedures

\begin{tabular}{ll}
\hline Ventriculoperitoneal shunt \\
\hline Creation of ventriculoatrial shunt \\
Ventriculopleural shunt w/ valve \\
\hline Shunt of cerebral ventricle to gallbladder \\
\hline Creation of lumboperitoneal shunt \\
\hline Revision of cerebral ventricular shunt \\
\hline Replacement of ventricular shunt \\
\hline Removal of ventriculoperitoneal shunt \\
\hline Removal of cerebral ventricular shunt \\
\hline Endoscopic exteriorization of third ventricle \\
\hline Endoscopic third ventriculostomy
\end{tabular}


TABLE 2. Patient demographics

\begin{tabular}{cc}
\hline \multicolumn{2}{c}{ Value } \\
\hline Age, yrs \\
\hline Mean (SD) & $13.9(10.3)$ \\
\hline Median & 12.3 \\
\hline Sex, $\mathrm{n}(\%)$ & $2308(51.9)$ \\
\hline Female & $2140(48.1)$ \\
\hline Male & $856(19.2)$ \\
\hline Functional lesion level (\%) & $508(11.4)$ \\
\hline Thoracic (flaccid lower extremities) & $1325(29.8)$ \\
\hline High lumbar (hip flexion present) & $877(19.7)$ \\
\hline Midlumbar (knee extension present) & $882(19.8)$ \\
\hline Low lumbar (foot dorsiflexion present)
\end{tabular}

Reproduced from Kim et al: J Neurosurg Pediatr [epub ahead of print August 24, 2018. DOI: 10.3171/2018.5.PEDS18160] with permission.

or earlier to those born in 2006 or later, thus separating the comparison groups by excluding all children born in 2004 or 2005.

Finally, post hoc analysis was performed using multivariate logistic regression to control for the effect of lesion level on observations made about hydrocephalus treatment rates by study site and by year of birth.

\section{Results}

We identified 4448 individuals with myelomeningocele from the 26 institutions in the NSBPR (Table 2),
$2308(51.89 \%)$ of whom were female and $2140(48.11 \%)$ of whom were male. The mean age at the time of the most recent clinic visit was 13.9 years (median 12.3 years, SD 10.3 years, range $0-82$ years). Figure 1 shows the age distribution of the included patients. Children younger than 1 year accounted for $12.5 \%$ of the total sample $(n=558)$.

We used functional lesion level (as defined by the NSBPR) as an assessment of neurological function. There were 856 patients (19.2\%) with a thoracic functional level (flaccid lower extremities); 508 patients (11.4\%) had highlumbar (hip flexion present), 1325 patients $(29.8 \%)$ had midlumbar (knee extension present), 877 patients (19.7\%) had low-lumbar (foot dorsiflexion present), and $882 \mathrm{pa}-$ tients $(19.8 \%)$ had sacral (foot plantar flexion present) functional levels.

Of all patients, 3558 (79.99\%) had undergone at least 1 surgical procedure for hydrocephalus treatment. There was no significant difference in the rates of treated hydrocephalus between male and female patients $(79.11 \%$ vs $80.81 \%$ respectively, $\mathrm{p}=0.158$ ). When considering only participants older than 12 months, the overall rate of hydrocephalus treatment was $80.90 \%$.

Univariate logistic regression demonstrated a significant association between the functional lesion level of myelomeningocele and treated hydrocephalus (Table 3): 789 of 856 patients $(92.2 \%)$ of patients with thoracic meningoceles, 454 of 508 patients $(89.4 \%)$ with high-lumbar, 1104 of 1325 patients (83.3\%) with midlumbar, 676 of 877 patients (77.1\%) with low-lumbar, and 535 of 882 patients $(60.7 \%)$ patients with sacral myelomeningoceles required treatment for hydrocephalus. More rostral functional lesion levels were associated with higher rates of

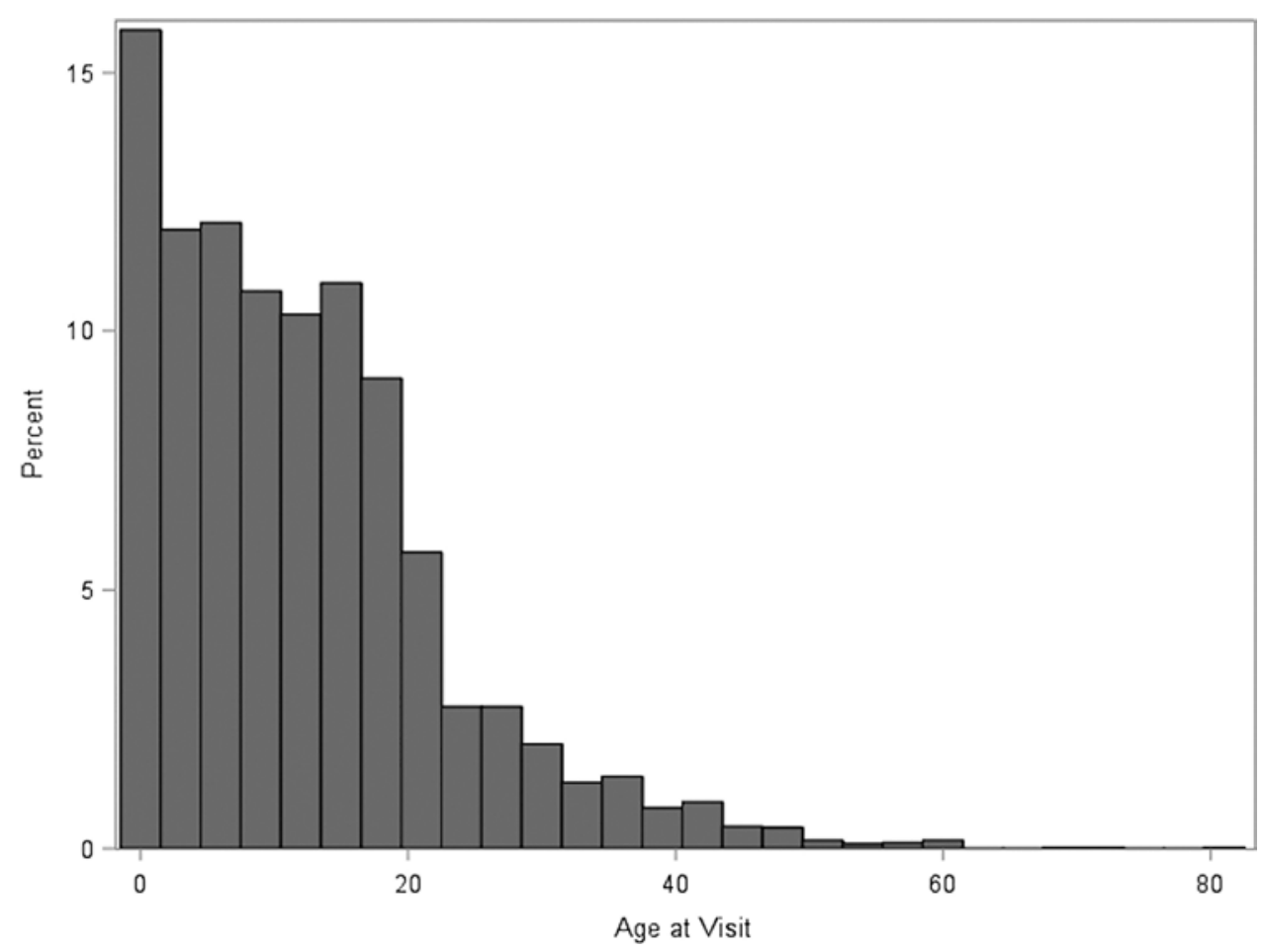

FIG. 1. Age (in years) of included patients at the most recent follow-up visit. Reproduced from Kim et al: $J$ Neurosurg Pediatr [epub ahead of print August 24, 2018. DOI: 10.3171/2018.5.PEDS18160] with permission. 
TABLE 3. Relationship between functional lesion level of myelomeningocele and treated hydrocephalus

\begin{tabular}{|c|c|c|c|c|c|}
\hline \multirow[b]{2}{*}{$\begin{array}{l}\text { Functional } \\
\text { Lesion Level }\end{array}$} & \multicolumn{2}{|c|}{ No. of Patients } & \multirow{2}{*}{\multicolumn{2}{|c|}{$\begin{array}{c}\text { OR } \\
\text { (vs sacral } \\
\text { level) }\end{array}$}} & \multirow[b]{2}{*}{$95 \% \mathrm{Cl}$} \\
\hline & $\begin{array}{c}\text { w/ Treated } \\
\text { Hydrocephalus }\end{array}$ & Total & & & \\
\hline Thoracic & 789 & 856 & 92.2 & 7.64 & $5.75-10.14$ \\
\hline High lumbar & 454 & 508 & 89.4 & 5.45 & $3.99-7.46$ \\
\hline Midlumbar & 1104 & 1325 & 83.3 & 3.24 & $2.66-3.95$ \\
\hline Low lumbar & 676 & 877 & 77.1 & 2.18 & $1.77-2.68$ \\
\hline Sacral & 535 & 882 & 60.7 & Ref & Ref \\
\hline Total & 3558 & 4448 & 80.0 & & \\
\hline
\end{tabular}

hydrocephalus treatment $(\mathrm{p}<0.0001)$. The OR for hydrocephalus treatment (with sacral functional lesion level as the reference) was 7.64 (95\% CI 5.75-10.14) in thoracic, 5.45 (95\% CI 3.99-7.46) in high-lumbar, 3.24 (95\% CI 2.66-3.95) in midlumbar, and 2.18 (95\% CI 1.77-2.68) in low-lumbar myelomeningoceles. Thus, there is a statistically significant increase in the odds for hydrocephalus treatment when any more rostral functional lesion level is compared with the sacral lesion level. This relationship is maintained with negligible change in odds ratios or confidence intervals when analysis is performed using only children 12 months or older.

A total of 26 sites participate in the NSBPR, with a mean enrollment of 136.9 individuals per institution (SD 101.5, median 154, range 1-363 patients; Fig. 2). Among institutions enrolling more than 10 patients ( 23 of 26 institutions), the rate of treated hydrocephalus ranged from $72 \%$ to $96 \%$. This difference in hydrocephalus treatment rate is statistically significant by chi-square analysis $(\mathrm{p}<$
0.001). There is also a statistically significant difference in proportion of patients with each functional lesion level at each site ( $p<0.001$, chi-square test). Nevertheless, when controlling for functional lesion level, the difference between sites remains statistically significant.

Univariate logistic regression analysis also demonstrated a significant decrease in the rates of treated hydrocephalus in children born in 2005 or later. Of the 2796 individuals born before 2005, 2296 (82.1\%) had treated hydrocephalus. Of the 1652 individuals born in 2005 or later, $1262(76.4 \%)$ had hydrocephalus treatment (OR 1.42, 95\% CI $1.22-1.65$; $p<0.001)$. When this analysis is repeated with 2002 and 2008 as the threshold years, there continues to be a statistically significantly higher rate of hydrocephalus treatment in the earlier period. However, when combined with sex and functional lesion level in a multivariate logistic regression model, only functional lesion level remains significant. Sex $(p=0.25)$ and year of birth $(p=0.086)$ did not show statistically significant association with hydrocephalus treatment (Table 4). When this analysis was repeated comparing children born in 2003 or earlier with those born in 2006 or later, we saw a significant difference in univariate analysis (OR $1.30,95 \%$ CI $1.10-1.54 ; \mathrm{p}=0.0018$ ) but no significant difference when controlling for lesion level $(p=0.49)$. As expected, given these findings, there is a statistically significantly higher proportion of more rostral functional lesion level among children born in the earlier epoch than those born in later epochs ( $\mathrm{p}<0.001$, chi-square test).

\section{Discussion}

The overall rate of treated hydrocephalus in patients with myelomeningocele enrolled in the NSBPR is $80 \%$, which is consistent with rates reported in the published lit-

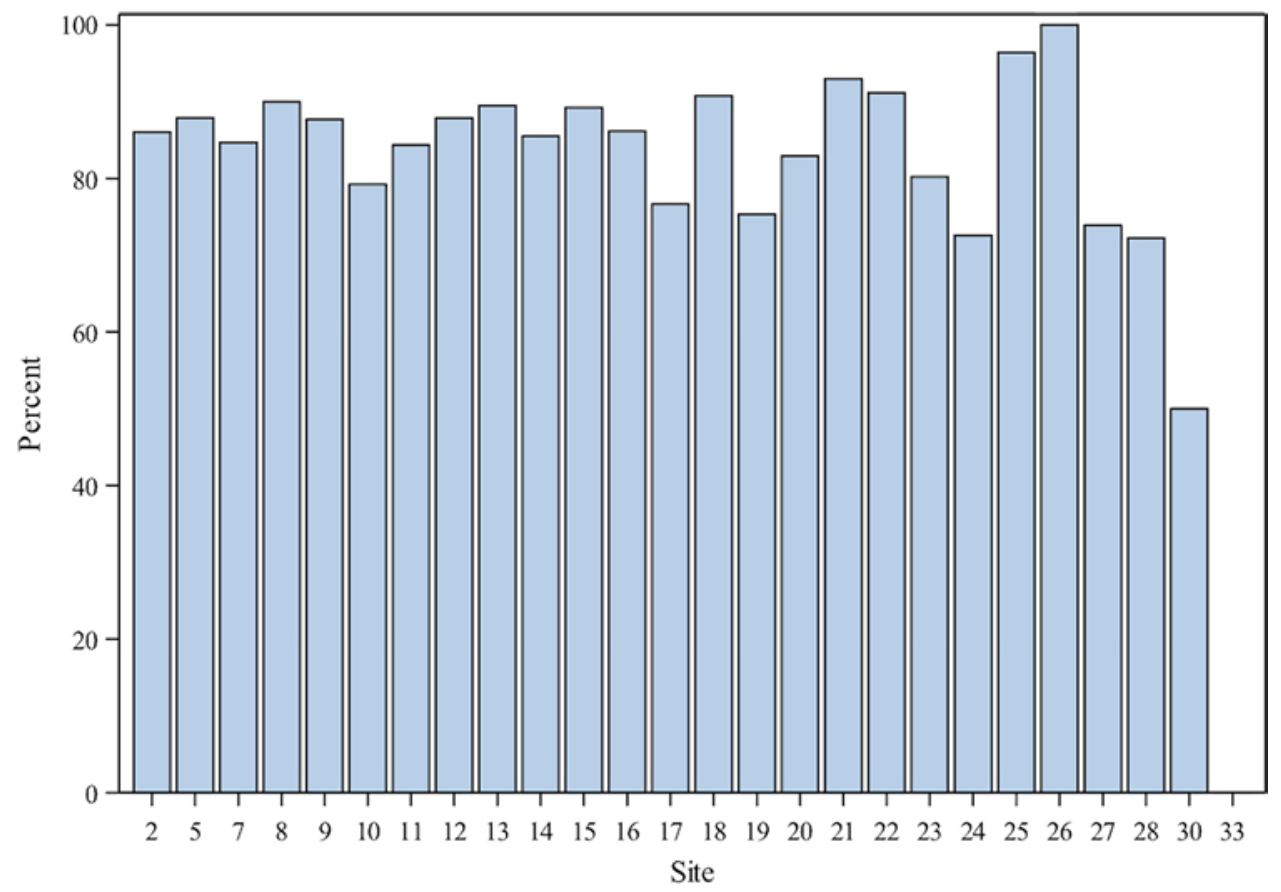

FIG. 2. Distribution of treated hydrocephalus by site. Figure is available in color online only. 
TABLE 4. Relationship between functional lesion level, sex, and year of birth with treated hydrocephalus

\begin{tabular}{ccc}
\hline Variable & OR & $95 \% \mathrm{Cl}$ \\
\hline Functional lesion level & & \\
\hline Thoracic & 7.33 & $5.51-9.77$ \\
\hline High lumbar & 5.41 & $3.96-7.40$ \\
\hline Midlumbar & 3.20 & $2.63-3.90$ \\
\hline Low lumbar & 2.19 & $1.78-2.70$ \\
\hline Sacral & Ref & Ref \\
\hline Sex & & \\
\hline Female & 1.10 & $0.94-1.28$ \\
\hline Male & Ref & Ref \\
\hline Year of birth & & \\
\hline Before 2005 & 1.15 & $0.98-1.34$ \\
\hline 2005 or later & Ref & Ref
\end{tabular}

erature. As expected, there is some variability among the institutions participating in the NSBPR. However, among sites enrolling more than 10 patients, the rates of treated hydrocephalus varied from $72 \%$ to $96 \%$, which appears to be slightly lower than rates in the published literature. ${ }^{1-4,6-8}$

Unfortunately, the available data in the NSBPR do not contain enough detail to explain this variation between sites. The version of registry questionnaire in use at the time of this analysis did not record the indication for treatment of hydrocephalus, nor did it collect data on clinical or radiographic patient parameters related to hydrocephalus, such as fontanelle characteristics, splayed sutures, biventricular diameter, or bradycardic/apneic episodes. ${ }^{8,15}$ In addition, very limited data on head circumference were collected (at the time of enrollment and annually if the child was younger than 3 years), which is insufficient for analysis.

It should also be noted that the registry questionnaire in use at that time did not record any data regarding timing of myelomeningocele closure. Although we estimate that less than $1 \%$ of patients enrolled in the NSBPR underwent prenatal closure, the available data do not allow us to compare rates of treated hydrocephalus between patients who have undergone prenatal surgery and those who have undergone postnatal surgery.

The data did demonstrate a clear correlation between functional lesion level of the myelomeningocele and the need for hydrocephalus treatment. By combining all patients with a functional lumbar level (high, mid, and low), we found that overall rates of treated hydrocephalus were $92.2 \%$ for thoracic-level, $82.4 \%$ for lumbar-level, and $60.7 \%$ for sacral-level myelomeningoceles. These rates can be compared with the single-institution data from Children's Hospital of Philadelphia, which reported shunting rates of $97 \%, 87 \%$, and $37 \%$, respectively, by functional level. ${ }^{10}$ Compared with the published single-center data, rates of treated hydrocephalus in the present study were similar but slightly lower in the thoracic and lumbar functional levels, but much higher in the sacral functional levels. The reason for this difference is not clear. While the correlation between functional lesion level and hydro- cephalus is not unexpected, it has not previously been explored with this large of a sample size.

The data also suggest a decrease in the rate of treated hydrocephalus in individuals born in 2005 or later compared with those born before 2005. This is consistent with our perception of a trend toward a higher threshold for treatment of hydrocephalus. In recent years, there has been a growing discussion about reducing treatment rates for hydrocephalus in patients with myelomeningoceles, arising in part due to concerns about the long-term sequelae of shunted hydrocephalus and the morbidity of multiple shunt operations in conjunction with the lower rates of CSF shunting reported in patients undergoing pre-

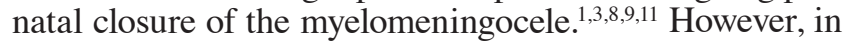
multivariate analysis, when controlling for lesion level, the effect of year of birth is lost. Therefore, we can report no such declining trend in hydrocephalus treatment rate.

Since it was established in 2008, the NSBPR questionnaire has been updated and expanded. Data are currently being collected in the third version of the registry questionnaire, which includes much more data on hydrocephalus, including clinical and radiographic parameters of the patient as well as the indications for some surgical procedures, including treatment of hydrocephalus. More analysis is indicated in the future to better understand the variation in the rates of treated hydrocephalus among institutions as well as the ultimate effect of neurocognitive parameters.

\section{Limitations}

In addition to the limitations on data included in the NSBPR noted above, there are important additional limitations. Individuals may have been lost to follow-up or have moved to a different NSBPR site. If an individual moves to a different participating site, his or her records are forwarded and the patient would be counted as a patient at the new site (site of most recent clinic visit). This may lead to inaccuracies in the analysis of hydrocephalus treatment rate by site. We estimate that less than $1 \%$ of patients move between centers each year. Therefore, this should be a minor error.

There is no validated assessment of the functional lesion level. While the NSBPR provides guidelines and descriptions of functional level, personnel at each site make a judgment about the level. Similarly, the decision to treat a patient's hydrocephalus is made by local surgeons and may vary between sites. While guidelines exist for making treatment decisions, for example, those from the MOMS trial, there may be variation in how these standards are applied. ${ }^{1,6}$

\section{Conclusions}

The rate of hydrocephalus treatment in patients with myelomeningocele in the NSBPR is $80 \%$, which is consistent with the rate in previously published literature. Our data demonstrate a clear association between functional lesion level of the myelomeningocele and the need for hydrocephalus treatment. While we hypothesized that hydrocephalus treatment had decreased over time, we saw no evidence that this is the case. 


\section{Acknowledgments}

The National Spina Bifida Patient Registry is funded by the National Center on Birth Defects and Developmental Disabilities, CDC, Atlanta, Georgia. Preparation of this manuscript was supported by CDC grant nos. 1UO1DDD000742.01, 1UO1DDD000766.01, and 1UO1DDD000772.01.

The development of the NSBPR has been successful due to the contributions of all the members of the NSBPR Coordinating Committee. Members of this committee during the collection of the data reported here were William Walker, Seattle Children's Hospital; Kathryn Smith, Children's Hospital, Los Angeles; Kurt Freeman, Oregon Health \& Science University, Portland; Pamela Wilson, Children's Hospital Colorado, Aurora; Kathleen Sawin, Children's Hospital of Wisconsin and Froedtert Hospital, Milwaukee (adult clinic); Jeffrey Thomson, Connecticut Children's Medical Center, and Shriners Hospital for Children, Springfield; Heidi Castillo, Texas Children's Hospital/Baylor College of Medicine, Houston; David Joseph, Children's of Alabama and University of Alabama at Birmingham; Jacob Neufeld, St. Luke's Boise Medical Center, Boise; Robin Bowman, Lurie Children's Hospital of Chicago, Chicago; Karen Ratliff-Schaub, Nationwide Children's Hospital, Columbus; Jim Chinarian, Children's Hospital of Michigan, Detroit; John Wiener, Duke University Medical Center, Durham; Mark Dias, Hershey Medical Center, Hershey; Tim Brei, Riley Hospital for Children, Indianapolis; Brad Dicianno, Children's Hospital of Pittsburgh, and University of Pittsburgh Medical Center, (adult clinic) Pittsburgh; Paula Peterson, Primary Children's Medical Center, Salt Lake City; Elaine Pico, UCSF, San Francisco, and Children's Hospital and Research Center, Oakland. The findings and conclusions in this report are those of the authors and do not necessarily represent the official position of the CDC.

\section{References}

1. Adzick NS, Thom EA, Spong CY, Brock JW III, Burrows PK, Johnson MP, et al: A randomized trial of prenatal versus postnatal repair of myelomeningocele. $\mathbf{N}$ Engl J Med 364:993-1004, 2011

2. Bowman RM, Boshnjaku V, McLone DG: The changing incidence of myelomeningocele and its impact on pediatric neurosurgery: a review from the Children's Memorial Hospital. Childs Nerv Syst 25:801-806, 2009

3. Chakraborty A, Crimmins D, Hayward R, Thompson D: Toward reducing shunt placement rates in patients with myelomeningocele. J Neurosurg Pediatr 1:361-365, 2008

4. Johnson MP, Sutton LN, Rintoul N, Crombleholme TM, Flake AW, Howell LJ, et al: Fetal myelomeningocele repair: short-term clinical outcomes. Am J Obstet Gynecol 189:482-487, 2003

5. Kim I, Hopson B, Aban I, Rizk EB, Dias MS, Bowman R, et al: Decompression for Chiari malformation type II in individuals with myelomeningocele in the National Spina Bifida Patient Registry. J Neurosurg Pediatr [epub ahead of print August 24, 2018. DOI: 10.3171/2018.5.PEDS18160]

6. Laskay NMB, Arynchyna AA, McClugage SG III, Hopson B, Shannon C, Ditty B, et al: A comparison of the MOMS trial results to a contemporaneous, single-institution, postnatal closure cohort. Childs Nerv Syst 33:639-646, 2017

7. Patet JD, Lapras C, Guilburd JN, Lapras C: [Spina bifida aperta-myelomeningocele. Hydrocephalus.] Neurochirurgie 34 (Suppl 1):47-52, 1988 (Fr)

8. Phillips BC, Gelsomino M, Pownall AL, Ocal E, Spencer HJ, O'Brien MS, et al: Predictors of the need for cerebrospinal fluid diversion in patients with myelomeningocele. J Neurosurg Pediatr 14:167-172, 2014
9. Piatt JH Jr: Treatment of myelomeningocele: a review of outcomes and continuing neurosurgical considerations among adults. J Neurosurg Pediatr 6:515-525, 2010

10. Rintoul NE, Sutton LN, Hubbard AM, Cohen B, Melchionni J, Pasquariello PS, et al: A new look at myelomeningoceles: functional level, vertebral level, shunting, and the implications for fetal intervention. Pediatrics 109:409-413, 2002

11. Sankhla S, Khan GM: Reducing CSF shunt placement in patients with spinal myelomeningocele. J Pediatr Neurosci 4:2-9, 2009

12. Sawin KJ, Liu T, Ward E, Thibadeau J, Schechter MS, Soe MM, et al: The National Spina Bifida Patient Registry: profile of a large cohort of participants from the first 10 clinics. J Pediatr 166:444-450, 450.e1, 2015

13. Stein SC, Schut L: Hydrocephalus in myelomeningocele. Childs Brain 5:413-419, 1979

14. Thibadeau JK, Ward EA, Soe MM, Liu T, Swanson M, Sawin KJ, et al: Testing the feasibility of a National Spina Bifida Patient Registry. Birth Defects Res A Clin Mol Teratol 97:36-41, 2013

15. Tulipan N, Wellons JC III, Thom EA, Gupta N, Sutton LN, Burrows PK, et al: Prenatal surgery for myelomeningocele and the need for cerebrospinal fluid shunt placement. J Neurosurg Pediatr 16:613-620, 2015

\section{Disclosures}

The authors report no conflict of interest concerning the materials or methods used in this study or the findings specified in this paper.

\section{Author Contributions}

Conception and design: Rocque, Hopson, Rizk, Dias, Bowman, Ackerman, Partington, H Castillo, J Castillo, Peterson, Blount. Acquisition of data: Rocque, Kim, Hopson, Rizk, Dias, Bowman, Ackerman, Partington, H Castillo, J Castillo, Peterson, Blount. Analysis and interpretation of data: all authors. Drafting the article: all authors. Critically revising the article: all authors. Reviewed submitted version of manuscript: all authors. Approved the final version of the manuscript on behalf of all authors: Rocque. Statistical analysis: Aban. Administrative/technical/material support: Rocque, Hopson, Rizk, Dias, Bowman, Ackerman, Partington, H Castillo, J Castillo, Peterson, Blount. Study supervision: Rocque.

\section{Supplemental Information \\ Online-Only Content}

Supplemental material is available with the online version of the article.

Appendix. https://thejns.org/doi/suppl/10.3171/2018.5. PEDS18161.

\section{Previous Presentations}

Data included in this manuscript were presented at the 45th Annual AANS/CNS Section on Pediatric Neurological Surgery meeting, Orlando, Florida, December 5-8, 2016, and at the Third World Congress on Spina Bifida Research \& Care, San Diego, California, March 16-19, 2017.

\section{Correspondence}

Brandon G. Rocque: University of Alabama at Birmingham, AL. brandon.rocque@childrensal.org. 